\title{
Production, characterization and evaluation of biochar from pod (Pisum sativum), leaf (Brassica oleracea) and peel (Citrus sinensis) wastes
}

\author{
G. Stella Mary ${ }^{1} \cdot$ P. Sugumaran ${ }^{1} \cdot$ S. Niveditha ${ }^{2} \cdot$ B. Ramalakshmi ${ }^{2}$. \\ P. Ravichandran ${ }^{1} \cdot$ S. Seshadri ${ }^{1}$
}

Received: 26 June 2015/ Accepted: 6 January 2016/Published online: 26 January 2016

(C) The Author(s) 2016. This article is published with open access at Springerlink.com

\begin{abstract}
Purpose Biochar has potential as a valuable tool for the agricultural industry with its unique ability to help build soil health, increase physical properties of soil, soil $\mathrm{pH}$, organic carbon content, conserve water and mitigate drought, reduce GHG emission, conserve nutrients, decrease fertilizer requirements, sequester carbon, increase crop productivity and serve as a most preferred habitat for microbes. In this study, three perishable biomass wastes viz. Pea pod (Pisum sativum), cauliflower leaves (Brassica oleracea) and orange peel wastes (Citrus sinensis) were carbonized and characterized for differential application.

Methods The biomass was subjected to carbonization at different temperatures from 100 to $600{ }^{\circ} \mathrm{C}$ for $1 \mathrm{~h}$. Biomass and biochar samples were characterized for proximate $(\mathrm{M}$, VM, FC, Ash), ultimate (CHNS-O), biochemical properties $(\mathrm{Ce}, \mathrm{He}, \mathrm{Li})$, thermo gravimetric analysis, $\mathrm{pH}, \mathrm{EC}$ and bulk
\end{abstract}

P. Sugumaran

sugumaranp@mcrc.murugappa.org

G. Stella Mary

stellamaryg@mcrc.murugappa.org

S. Niveditha

nive_92@yahoo.co.in

B. Ramalakshmi

ramabonjour@gmail.com

P. Ravichandran

ravichandranp@mcrc.murugappa.org

S. Seshadri

seshadris@mcrc.murugappa.org

1 Shri A.M.M. Murugappa Chettiar Research Center, Taramani, Chennai, Tamil Nadu, India

2 Jeppiaar Engineering College, Chennai, Tamil Nadu, India density. The biochars were also analyzed through SEM and FTIR for identification of pore size and functional groups. Results The char yield was high in cauliflower leaf $(30.16 \%)$, followed by orange peel $(25.54 \%)$ and pea pod $(21.154 \%)$ at $300{ }^{\circ} \mathrm{C}$. The total organic carbon $(11.61 \%)$, total negative surface anions $\left(4.25 \mathrm{mmol} \mathrm{H}^{+}\right.$eq/g C) and water holding capacity (200\%) were high in pea pod biochar. The SEM images of biochar samples showed plane cleavage surfaces with broken edges. The surface functional groups of all the three biochar samples were hydroxyl, methyl, carboxylic and alkene groups.

Conclusion The pea pod and cauliflower leaf biochar showed higher values of organic carbon, total surface anions, water holding capacity and mineral content and performed as best soil amendment than orange peel biochar. These biochar can be used as an effective medium for increasing soil carbon, irrigation efficiency and efficient disposal of agricultural waste-biomass.

Keywords Biochar - Sequester carbon - Perishable biomass - Pea pod $\cdot$ Cauliflower leaves $\cdot$ Orange peel

\section{Introduction}

Climate change is one of the most important challenges faced by the modern world. In many developing countries efforts are taken to reduce avoidable greenhouse gas emissions or off-setting unavoidable emissions through sequestration of C (Lehmann et al. 2006).

Biomass is the world's fourth largest energy source and the first in developing countries representing 14 and $35 \%$ of primary energy (Hall et al. 1992). Globally, biomass has an annual primary production of 220 billion oven-dry tons (odt) (Hall and Rosillo-Calle 1998) and India produces 
nearly 370 million tons of agricultural, forest/biomass wastes per year (Pappu et al. 2007). Among all the available lignocellulosic biomass, agricultural wastes such as corn stover, wheat straw and rice straw are produced in huge amounts globally (Loow et al. 2015). Biomass stands a greater chance of prevailing as a good source for the production of bio-char, which in turn can be a solution for waste management. The abundance and availability of agricultural by-products make them good raw materials for biochar production and excellent sources for waste management (Sugumaran and Seshadri 2009).

Bio-char is a fine-grained, black, solid, carbon-rich (70-80\%) porous substance produced from thermal decomposition of biological wastes (e.g. wood waste, agricultural biomass waste and manures) in the absence of oxygen at relatively low temperature $\left(<300{ }^{\circ} \mathrm{C}\right)$ (Lehmann et al. 2002). Biochar has large surface area and high porosity, tending to increase with increasing pyrolysis temperature until around $850{ }^{\circ} \mathrm{C}$ (Lua et al. 2004; Brown et al. 2006). Many biochar products have alkaline pH (Gaskin et al. 2008; Spokas et al. 2012), which can decrease soil acidity, creating a more favorable habitat for many plants and microbes. Biochar has high capacity to adsorb cations and anions from solutions, including a variety of polar and nonpolar organic compounds. Wood-derived biochar have a cation exchange capacity (CEC) up to $490 \mathrm{cmol} \mathrm{C/kg} \mathrm{(Radlein} \mathrm{et} \mathrm{al.} \mathrm{1996)} \mathrm{and} \mathrm{an} \mathrm{anion}$ exchange capacity (AEC) of $88.2 \mathrm{cmol} \mathrm{C/kg}$ (Fujita et al. 1991). Biochar application to the soil has been reported to boost soil fertility and improve soil quality resulting in increased crop yields. Soil benefits include raising soil $\mathrm{pH}$, increasing water holding capacity, improving cation exchange capacity (CEC) and retaining nutrients (Glaser et al. 2001; Lehmann et al. 2003, 2006; Gaskin et al. 2008; Laird et al. 2010; Novak et al. 2012). Biochar is a low-cost product and has been tipped as an excellent soil amendment for sequestering carbon, for increasing organic carbon, water retention and to provide a preferred habitat for soil microbes (Atkinson et al. 2010; Sohi et al. 2009; Stavi and Lal 2013).

In the present study, perishable wastes such as pea pods, cauliflower leaves and orange peel wastes were used for the production of biochar and both the biomass and biochar were characterized for proximate, ultimate, biochemical, thermo gravimetric analysis, pH, EC, Bulk density and water holding capacity.

\section{Materials and methods}

\section{Biomass collection, processing and characterization}

Cauliflower leaf (CL), orange peel (OP) and pea pod (PP) wastes were collected from Thiruvanmiyur, Chennai, Tamil Nadu, processed (Sugumaran and Seshadri 2009) and subjected for proximate, ultimate and biochemical properties such as moisture, volatile matter, fixed carbon, ash [ASTM D-3172-89 (2002)], cellulose, hemicelluloses and lignin (Goering and Van Soest 1970). After drying in a hot air oven at $110^{\circ} \mathrm{C}$ for $24 \mathrm{~h}$, they were pulverized to fine powder, sieved and used for further characterization and biochar production.

The fine powdered (40 mesh size) samples were used for elemental (CHNS-O) analysis using Perkin-Elmer 2400 Series. Thermal analysis (DTA/TGA) was carried out using Perkin-Elmer STA 6000, simultaneous Thermal Analyzer and the devolatilization rate of the biomass wastes was determined. TGA of each sample was recorded from 40 to $800{ }^{\circ} \mathrm{C}$ at a heating rate of $10{ }^{\circ} \mathrm{C} / \mathrm{min}$ under the nitrogen atmosphere $\left(\mathrm{N}_{2}\right.$ with a flow rate of $\left.90 \mathrm{~mL} / \mathrm{min}\right)$ and the weight loss at different temperatures was recorded.

\section{Biochar production and characterization}

\section{Biochar yield at different temperatures}

Air dried biomass samples were pyrolyzed in an electrical muffle furnace at different temperature ranging from 200 to $600{ }^{\circ} \mathrm{C}$ for $1 \mathrm{~h}$. The percentage of biochar yield was calculated using the equation described below (Sadaka et al. 2014).

Yield $_{\text {biochar }}=\frac{m_{\text {biochar }}}{m_{\text {raw }}} \times 100 \%$,

where Yield $_{\text {biochar }}=$ mass yield of biochar, $\%$; $m_{\text {biochar }}=$ mass of biochar, $\mathrm{kg} ; m_{\text {raw }}=$ mass of raw biomass, $\mathrm{kg}$.

\section{Physical and chemical characteristics}

The surface morphological changes of biochar samples were investigated using a scanning electron microscope (SEM, Make: JEOL, Japan) equipped with an energy dispersion X-ray spectroscopy (EDX).

The $\mathrm{pH}$, electrical conductivity (EC) and bulk density of the biochar samples were determined by procedures outlined earlier (Ahmedna et al. 1997). For pH determination, 1 \% (w/ w) suspension of biochar in de-ionized water was prepared and the suspension was heated to $90{ }^{\circ} \mathrm{C}$ with stirring for $20 \mathrm{~min}$. The suspension was then allowed to cool to room temperature and the $\mathrm{pH}$ was measured using $\mathrm{pH}$ meter (Ecoscan, Eutech, Singapore). For EC determination, $1 \%$ (wt/wt) solution of biochar in water was stirred at room temperature for $20 \mathrm{~min}$, the electrical conductivity was measured using an Ecoscan conductivity meter (Eutech, Singapore) and values were presented in micro Siemens $(\mu \mathrm{S})$.

For bulk density, a glass cylinder $(25 \mathrm{ml})$ was filled to a specified volume with 40 mesh powder biochar, dried in an 
oven at $80{ }^{\circ} \mathrm{C}$ overnight. The cylinder was tapped for 1-2 min to compact the char and the bulk density was calculated and presented as $\mathrm{g} / \mathrm{ml}$ following the formula (Ahmedna et al. 1997):

$$
\begin{aligned}
\text { Bulk density }(\%)= & \frac{\text { Weight of dry material }(\mathrm{g})}{\text { Volume of packed dry materials }(\mathrm{ml})} \\
& \times 100,
\end{aligned}
$$

Total negative surface anions (TNA) in biochar samples were determined following Bohem (1994). A small amount of bio-char $(0.25 \mathrm{~g})$ was mixed with $25 \mathrm{ml}$ of $0.1 \mathrm{M} \mathrm{NaOH}$ containing $500 \mathrm{ml}$ conical flaks and stirred for $20 \mathrm{~h}$. After stirring, the sample was filtered through $0.45 \mu \mathrm{m}$ pore size filter. Then $10 \mathrm{ml}$ of filtrate and $15 \mathrm{ml}$ of standard $0.1 \mathrm{M}$ $\mathrm{HCl}$ were mixed and base titrated against $0.1 \mathrm{M} \mathrm{NaOH}$. The volume of $\mathrm{NaOH}$ required to neutralize the sample was converted to total surface charges. The total surface anion capacity was expressed as $\mathrm{mmol} \mathrm{H}^{+}$eq/g C.

Total organic carbon content of different biochar samples were analyzed using total organic carbon (TOC) analyzer with solid sample module (SSM)-(Make-SHIMADZU-Model TOC-L and SSM-5000A).

Water holding capacity was determined by following the methodology detailed by Dugan et al. (2010). Twenty grams of air-dried biochar sample, in triplicate, was put in a plastic container and placed in a dish of water. This was allowed to saturate for $6 \mathrm{~h}$. The container was removed from the water and covered with cling-film to prevent loss of water by evaporation. It was then hanged on a retort stand overnight to allow drainage. All samples were allowed to drain for the same amount of time. The percentage of water holding capacity was calculated using the following equation:

Water holding capacity $(\%)=\frac{M_{2}-M_{3}}{M_{3}-M_{1}} \times 100$,

Then, biochar was carefully removed from the container, put in a pre-weighed container $\left(M_{1}\right)$ and the total weight of moist biochar with container $\left(M_{2}\right)$ was taken. The samples were then dried in an oven at $105{ }^{\circ} \mathrm{C}$ until no further water loss occurred and reweighed to record the oven-dried sample $\left(M_{3}\right)$.

The surface chemistry of biochar samples was analyzed through FTIR transmission spectra (Gomez-Serrano et al. 1999) recorded using a Thermo Nicolet Avatar 370 FTIR spectrophotometer in the wave number range of $4000-400 \mathrm{~cm}^{-1}$. The char samples were ground with $\mathrm{KBr}$ (AR grade) at a ratio of roughly $1 / 1000$. Five hundred milligrams $(2 \mathrm{mg})$ of oven-dried $\left(110{ }^{\circ} \mathrm{C}\right.$ for $\left.12 \mathrm{~h}\right)$ fine powder was made into a pellet by continuously pressing at $5 \mathrm{ton} / \mathrm{cm}^{2}$ for $1 \mathrm{~min}$ and $17 \mathrm{ton} / \mathrm{cm}^{2}$ for 2 min using a hydraulic pump. After preparation, the pellet was analyzed immediately, and the spectra were recorded to $1 \mathrm{~cm}^{-1}$ resolution. A pellet prepared with an equivalent quantity of pure $\mathrm{KBr}$ powder was used as control.
Table 1 Proximate, ultimate and biochemical analysis of different biomass wastes

\begin{tabular}{llll}
\hline Parameters & \multicolumn{2}{l}{ Biomass wastes (wt\%) dry basis } \\
\cline { 2 - 4 } & Pea pod (PP) & Cauliflower leaves (CL) & Orange peel (OP) \\
\hline Proximate analysis & & $18.86 \pm 1.30$ & $5.50 \pm 0.70$ \\
Ash & $3.50 \pm 1.40$ & $9.00 \pm 1.40$ & $13.0 \pm 1.40$ \\
Moisture & $7.0 \pm 1.41$ & $51.0 \pm 2.83$ & $70.0 \pm 1.70$ \\
Volatile matter & $78.0 \pm 1.41$ & $39.0 \pm 4.34$ & $24.1 \pm 1.75$ \\
Fixed carbon & $18.0 \pm 2.67$ & & 40.43 \\
Ultimate (elemental) analysis ${ }^{\mathrm{a}}$ & 31.80 & 4.83 \\
Carbon & 39.32 & 3.20 & 1.56 \\
Hydrogen & 4.75 & 4.01 & 0.27 \\
Nitrogen & 2.40 & 1.59 & 52.90 \\
Sulfur & 0.23 & 59.40 & 0.11 \\
Oxygen & 53.30 & 0.10 & \\
H/C & 0.12 & & $54.10 \pm 1.75$ \\
Biochemical analysis & & $40.00 \pm 4.34$ & $49.00 \pm 4.24$ \\
Cellulose & $45.0 \pm 2.67$ & $50.00 \pm 2.83$ & $12.00 \pm 2.83$ \\
Hemi cellulose & $41.00 \pm 1.09$ & $8.0 \pm 0.50$ & \\
Lignin & $3.00 \pm 1.41$ &
\end{tabular}

Values are mean \pm standard deviation of three replicates

${ }^{\text {a }}$ Results based on one time analysis 
46

Int J Recycl Org Waste Agricult (2016) 5:43-53

Fig. 1 Thermos gravimetric analysis (TGA) of different biomass. a Thermo gravimetric (TGA and DTG) analysis of pea pods. b Thermos gravimetric (TGA and DTG) analysis of cauliflower leaves. c Thermo gravimetric (TGA and DTG) analysis of orange peels

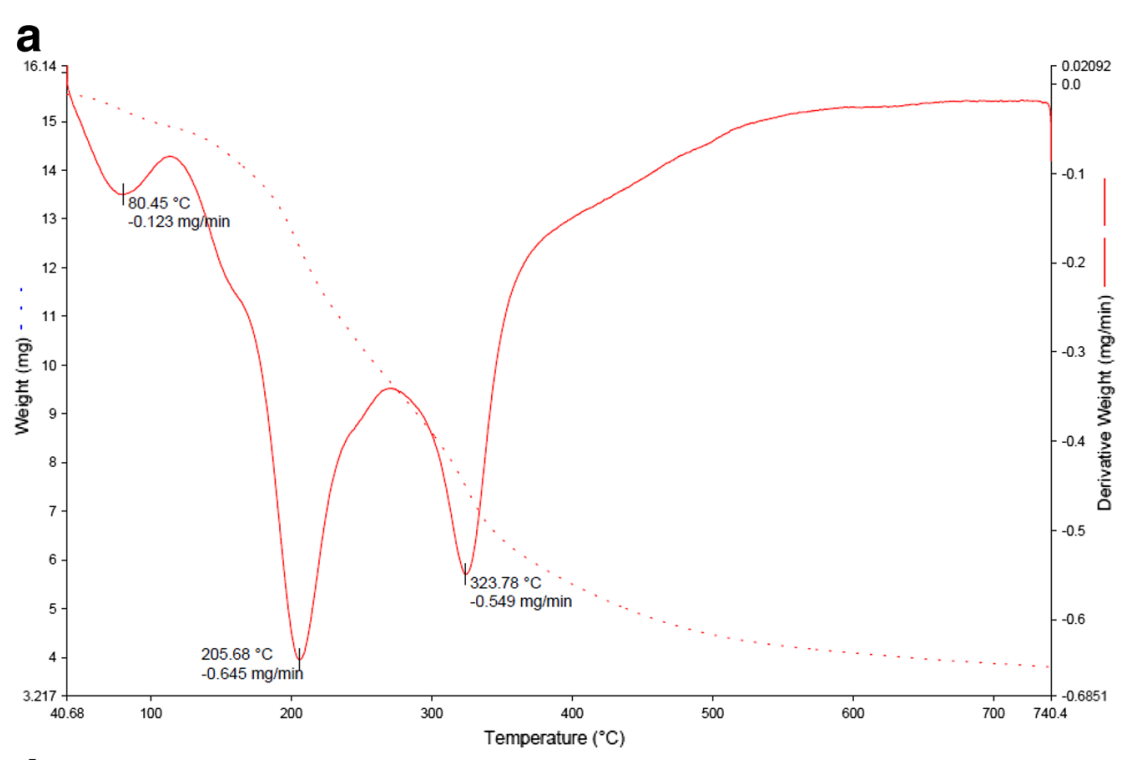

b
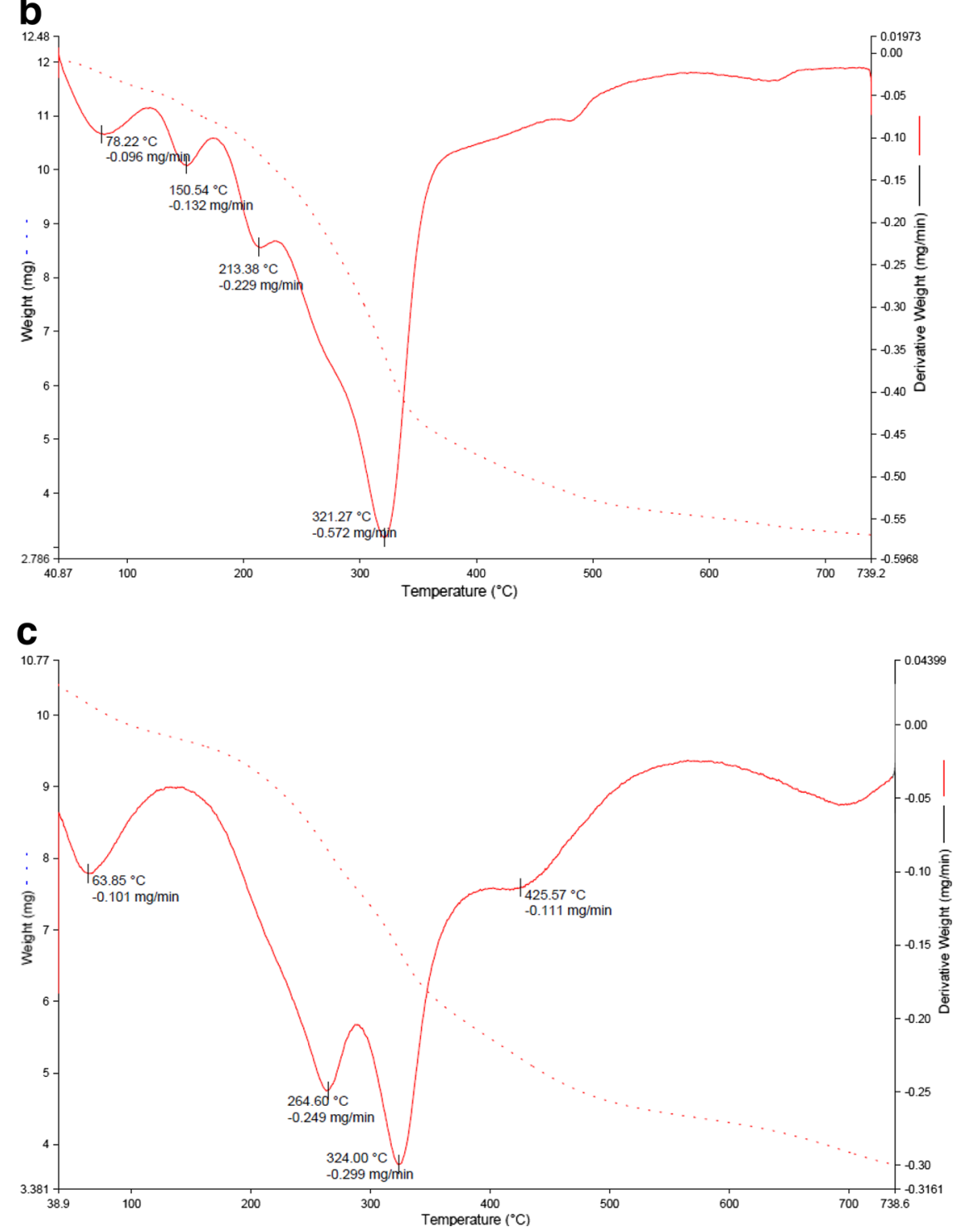

Springer 


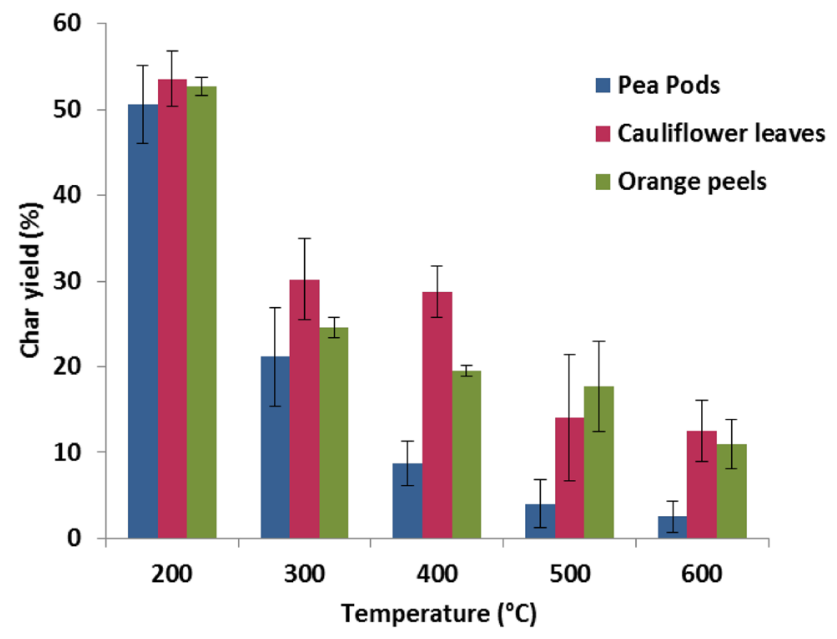

Fig. 2 Effect of pyrolysis temperature on the yields of three biomass wastes

\section{Statistical analysis}

All the experiments were carried out in triplicate and the results were expressed in average values.

\section{Results and discussion}

\section{Physiochemical characterization of biomass}

The proximate analyses of the biomass samples viz. moisture (M), ash (A), volatile matter (VM) and fixed carbon (FC) are presented in Table 1. While the moisture percentage ranged between 7 and $13 \%$, ash ranged from 3.50 to $18.86 \%$, and volatile matter and fixed carbon ranged between $51-78 \%$ and $18-39 \%$, respectively. Orange peels (OP) recorded higher moisture (13\%), followed by cauliflower leaves (CL) and pea pods (PP) 9 and $7 \%$, respectively. The volatile matter was high in PP (78\%) followed by OP (70\%). The fixed carbon (39\%) content was high in CL (39\%) and OP (24\%) and the values for PP were very low. While the results observed in this study are very closer to the earlier reports (Iyer et al. 2002; Sugumaran et al. 2012), they indicate the uniqueness of the biomass samples studied. When the biomass was classified based on ash content as low $(<5 \%)$, medium $(5-10 \%)$ and high $(>10 \%)$ (Iyer et al. 2002), the PP was low, CL was medium and OP was high.

The $\mathrm{C}, \mathrm{H}, \mathrm{N}, \mathrm{O}$ elemental analysis results of different agricultural wastes $(43.8-58.30,2.6-7.0,0.4-6.8$ and $32.05-50.20 \%$ ) were almost similar to earlier reports (Budinova et al. 2006; Sugumaran 2009; Sugumaran et al. 2012). The C, H, N, O composition analysis of different biomass wastes (Table 1) shows that $\mathrm{OP}$ recorded higher $\mathrm{C}$
$(40.43 \%)$ and $\mathrm{H}(4.83 \%)$ with low $\mathrm{N}(1.56 \%)$ content. CL recorded high $\mathrm{N}(4.01 \%)$ and low carbon content $(31.80 \%)$. The amount of oxygen $(53 \%)$ was almost similar in all the biomass samples. The hydrogen to carbon ratio $(\mathrm{H}: \mathrm{C})$ is a term often used to measure the degree of aromaticity and maturation of the biochar, which is linked to their long-term stability in the environment (Schmidt and Noack 2000). All biochar samples in this study had $\mathrm{H}: \mathrm{C}$ ratio $<0.12$ indicating a graphite-like structure in the biochar. Similar results were reported by Krull et al. (2009).

Cellulose and lignin are generally recognized as major components of the biomass and lignocellulosic materials can be regarded as a mixture of $40-80 \mathrm{wt} \%$ of cellulose, $15-30 \mathrm{wt} \%$ of hemicelluloses and 10-25 wt $\%$ of lignin (Carrier et al. 2011). In the present study, the biochemical properties like cellulose, hemi-cellulose and lignin ranged between $40-54.10,41-50$ and $3-12.0 \%$, respectively (Table 1). While the cellulose $(54.10 \%)$ and lignin (12\%) content was high in OP, the hemicellulose content was almost similar in CL (50\%) and OP (49 \%). Lignin content was very low (3\%) in PP than in other biomass samples. Though these values are different from earlier reports, they fall under the broader range values obtained in different biomass samples reported earlier (Sugumaran 2009; Sugumaran et al. 2012).

\section{Thermo gravimetric analysis}

It is well known that, in Pyrolysis, temperature plays an important role in product distribution, yield and characteristics of carbon production (Putun et al. 2002; Srikanth et al. 2004). In the present study, four weight loss stages were observed in OP and CL and three stages in PP (Fig. 1). The 1st stage indicating the loss of entrapped water molecules was in the range between 5.8 and $\sim 6.9 \%$ at $\sim 100{ }^{\circ} \mathrm{C}$ (Shak and $\mathrm{Wu} 2014$ ). In the 2 nd stage, maximum devolatilisation was observed in PP $(\sim 59 \%)$ followed by OP $(\sim 55 \%)$ at temperature between $\sim 150$ and $260{ }^{\circ} \mathrm{C}$ where maximum moisture content gets eliminated and cellulose starts decomposing. In the $3 \mathrm{rd}$ stage, the cellulose and lignin components as well as other complex aromatic structures get decomposed (Teh et al. 2014). Maximum devolatilisation was noticed in CL $(\sim 42 \%)$ followed by OP $(\sim 31 \%)$ at 200 and $450{ }^{\circ} \mathrm{C}$. Two biomass wastes could withstand the fourth stage and the corresponding devolatilization rate was $\sim 3.4 \%$ in $\mathrm{OP}$ and $\sim 2.3 \%$ in $\mathrm{CL}$ at $400-700{ }^{\circ} \mathrm{C}$, respectively. Among the samples tested, PP waste decomposed completely at 3rd stage, whereas OP and CL biomass decomposed at 4th stage due the presence of high lignin content of biomass. According to Yang et al. (2006), the whole process generally proceeds through a series of complex reaction 

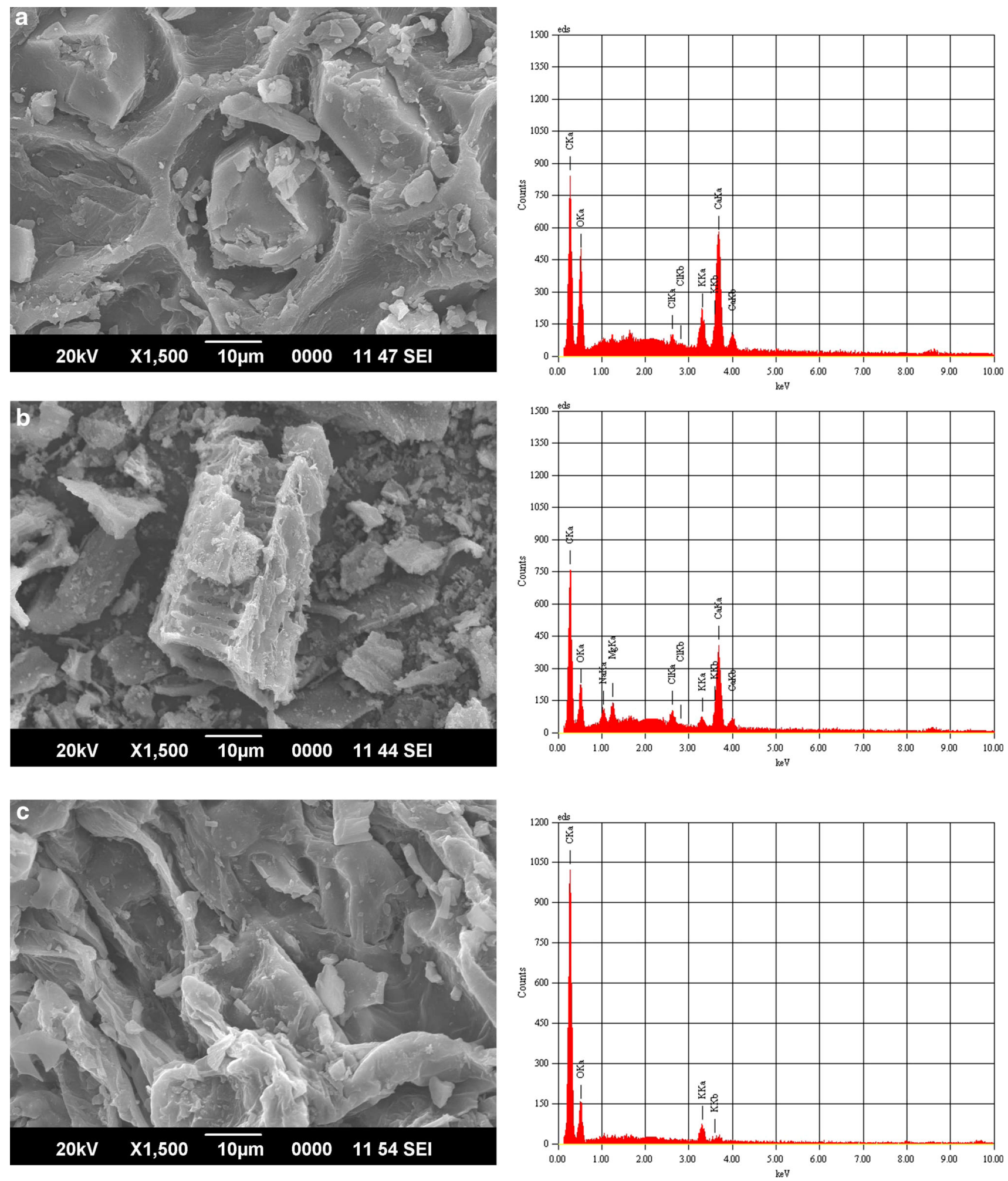

Fig. 3 Scanning electron micrographs (SEM) and EDX spectrograms of different biochar samples. SEM with EDX spectrograms of a pea pods; b cauliflower leaves; c orange peels

pathway or divides into four ranges, where $<220^{\circ} \mathrm{C}$ is for moisture evolution, $220-315{ }^{\circ} \mathrm{C}$ for predominantly hemicellulose decomposition, $315-400{ }^{\circ} \mathrm{C}$ for cellulose decomposition and $>400{ }^{\circ} \mathrm{C}$ for lignin decomposition. From the results it is clear that the devolatilization is specific to the inherent composition of the biomass studied 
Table 2 Physical and chemical characteristics of the biochars derived from different biomass wastes

\begin{tabular}{lrcc}
\hline Parameters & \multicolumn{3}{l}{ Biochar $(\mathrm{wt} \%)$ dry basis } \\
\cline { 2 - 4 } & Pea pod $(\mathrm{PP})$ & Cauliflower leaves $(\mathrm{CL})$ & Orange peel $(\mathrm{OP})$ \\
\hline $\mathrm{pH}$ & $8.84 \pm 0.08$ & $9.84 \pm 0.00$ & $9.43 \pm 0.17$ \\
Electrical conductivity $(\mu \mathrm{s} / \mathrm{cm})$ & $589 \pm 0.10$ & $1310 \pm 0.15$ & $231 \pm 0.18$ \\
Bulk density $(\mathrm{g} / \mathrm{ml})$ & $0.65 \pm 0.01$ & $0.37 \pm 0.00$ & $0.46 \pm 0.00$ \\
Water holding capacity $(\%)$ & $200 \pm 1.00$ & $200 \pm 0.81$ & $132 \pm 1.10$ \\
Total negative ions $\left(\mathrm{mmol} \mathrm{H} \mathrm{H}^{+}\right.$eq/g C) & $4.25 \pm 0.21$ & $4.15 \pm 0.21$ & $4.05 \pm 0.07$ \\
Total organic carbon $(\%)$ & $11.61 \pm 0.20$ & $11.09 \pm 0.00$ & $10.85 \pm 0.00$ \\
\hline
\end{tabular}

Values are mean \pm standard deviation of three replicates
(Yang et al. 2006; Yagmur et al. 2008; Sugumaran 2009; Sugumaran et al. 2012).

\section{Biochar production and characterization}

Several studies indicate that the yield of biochar is highly dependent on the pyrolysis conditions such as temperature, heating rate and heating time (Tsai et al. 2007; Uzun et al. 2006) and is also greatly influenced by chemical, physical and biological properties of the biomass (Knoepp et al. 2005; Lehmann 2007; Chan and Xu 2009; Basta et al. 2011). Biochar yield was found inversely proportional to temperature in all the samples subjected to biochar production at different temperatures from 200 to $700{ }^{\circ} \mathrm{C}$ for $1 \mathrm{~h}$ in the absence of Oxygen (Fig. 2). The optimum temperature for char yield was $300{ }^{\circ} \mathrm{C}$ where maximum values were observed in CL $(30.16 \%)$, OP $(24.54 \%)$ and PP $(21.14 \%)$. The char yield decreased rapidly with increasing temperature from 200 to $700{ }^{\circ} \mathrm{C}$. Similar results were reported for other agricultural by-products such as wheat-straw (32.40-22.8\%), corn-straw (35.50-24.90\%) and peanut-shell (36.80-25.80 \%) biochar samples where the char yield reduced as the pyrolysis temperature was increased from 400 to $700{ }^{\circ} \mathrm{C}$ and held constant for $1.5 \mathrm{~h}$ (Gai et al. 2014). In the pyrolysis process, lignin is the main component responsible for higher char formation, while hemicelluloses and cellulose contribute more volatile components (Sugumaran and Seshadri 2009; Maia et al. 2011; Sugumaran et al. 2012). In this study, the lignin content and char yield both were high in CL and OP.

The SEM-EDX analysis of the biochar samples is given Fig. 3. The SEM images of PP biochar showed that plane cleavage surface as the pyrolysis process would have stabilized the volatile hydrocarbons, smoothening the surface of biochar. The SEM image of CL biochar was like a molded skeleton with small pores and uneven surface structure. But in OP SEM image, the biochar had broken edges with tarry deposits on the surface. Generally, these biomass wastes contain low lignin and high volatile matter content which affects the pore creation in biochar (Lehmann, et al. 2011). The energy dispersion X-ray spectroscopy (EDX) of three different biochar samples indicated that the CL biochar has more minerals (C, O, Na, Cl, K, $\mathrm{Ca}, \mathrm{Mg}$ ) followed by $\mathrm{PP}(\mathrm{C}$, $\mathrm{O}, \mathrm{Cl}, \mathrm{K}, \mathrm{Ca})$ and $\mathrm{OP}$ biochar $(\mathrm{C}, \mathrm{O}, \mathrm{K})$, where these mineral agglomerates are close to the values reported earlier (Varela Milla et al. 2013).

The $\mathrm{pH}$ of the carbon directly impacts the adsorption process when the carbon is used in filtration process. Therefore, a neutral $\mathrm{pH}$ is generally preferred. Many biochar products have alkaline $\mathrm{pH}$ (Gaskin et al. 2008; Spokas et al. 2012) and the biochar samples in this study also recorded alkaline pH values (8.84-9.84). Electrical Conductivity of the biochar is responsible for exchange of ions. CL biochar recorded high EC $(1310 \mu \mathrm{S} / \mathrm{cm})$ followed by PP and OP. These results were similar to those of Lehmann (2007) and Liu and Zhang (2012) demonstrating that the properties of biochar were greatly dependent on the production procedure and type of raw material. Bulk density of biochar, differing according to the raw materials used, is that of the material comprising multiple particles and includes the macro porosity within each particle and the inter-particle voids. Bulk density of biochar samples in this study varied from 0.37 to $0.65 \mathrm{~g} / \mathrm{ml}$. Maximum bulk density was recorded in PP $(0.65 \mathrm{~g} / \mathrm{ml})$ followed by OP $(0.46 \mathrm{~g} / \mathrm{ml})$ and CL $(0.37 \mathrm{~g} / \mathrm{ml})$.

Biochar carbon is made up of easily degradable organic carbon compounds and very stable, polycondensed aromatic carbon structures (black carbon). Balck carbon content is an important criterion for characterizing biochar and also reflects the biochar's stability in the soil (EBC, 2012). In this study, the PP biochar recorded max. TOC $(11.61 \%)$ followed by CL (11.09\%) and OP (10.85\%). However, the total organic carbon content varied among biochar samples (Novak et al. 2009; Rondon et al. 2007; Sohi et al. 2010). The total negative surface anions play a vital role in the absorption of nutrients available in the soil and water. The total negative anions ranged from 4.05 to $4.25 \mathrm{mmol} \mathrm{H}^{+} \mathrm{eq} / \mathrm{g} \mathrm{C}$ (Table 2). It was high in PP biochar $\left(4.25 \mathrm{mmol} \mathrm{H}^{+} \mathrm{eq} / \mathrm{g} \mathrm{C}\right)$ followed by CL $\left(4.15 \mathrm{mmol} \mathrm{H}^{+}\right.$eq/g C) and $\mathrm{OP}(4.05 \mathrm{mmol}$ $\mathrm{H}^{+}$eq/g C). The amount of negative surface anions recorded in this study was higher than that reported earlier (Novak et al. 2009). This could be attributed to the presence of nitrogen $(\mathrm{N})$ and oxygen $(\mathrm{O})$ heterocycles that are responsible for the origin of negative surface anions in biochar. A 
FT-IR Spectra of Peas Pods Carbon

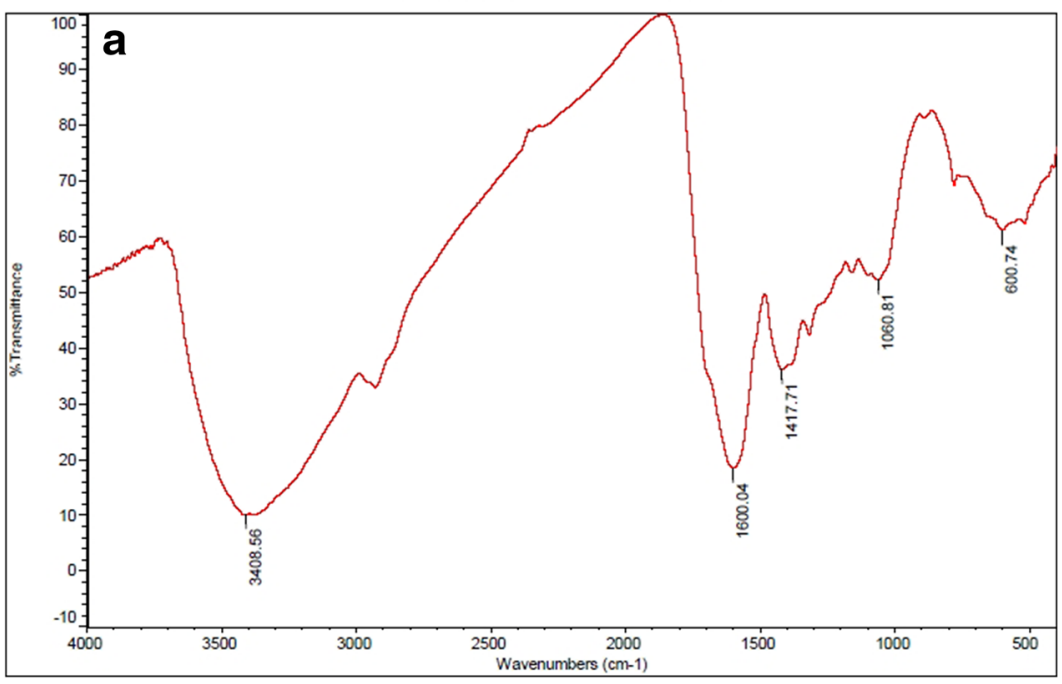

FT-IR Spectra of Cauliflower Carbon

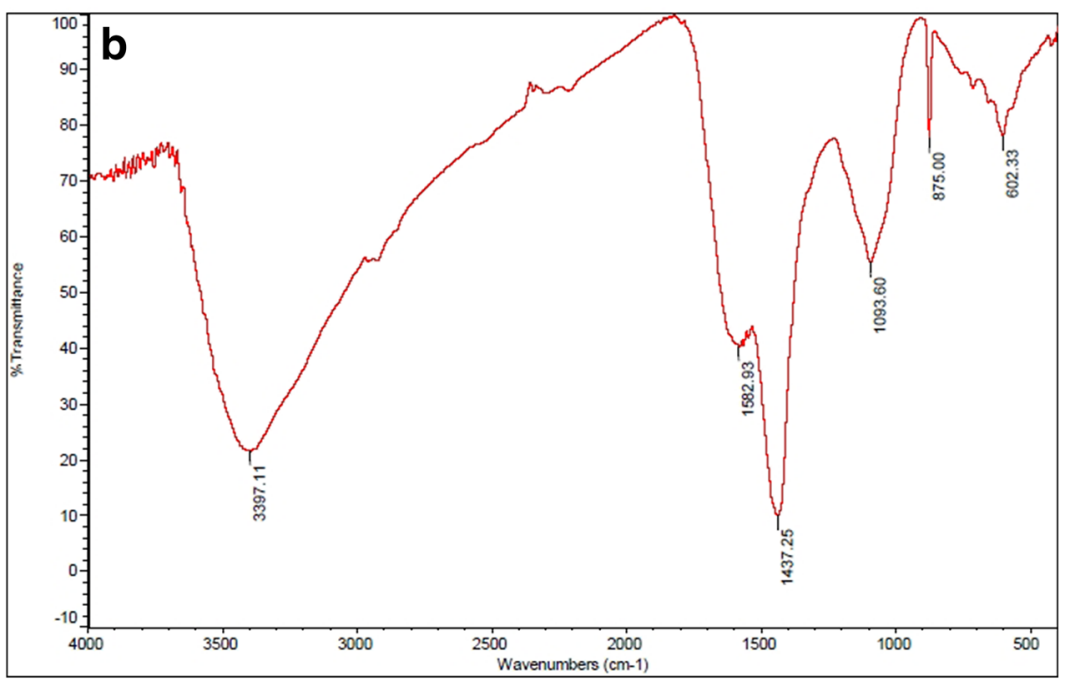

FT-IR Spectra of Orange Peels Carbon

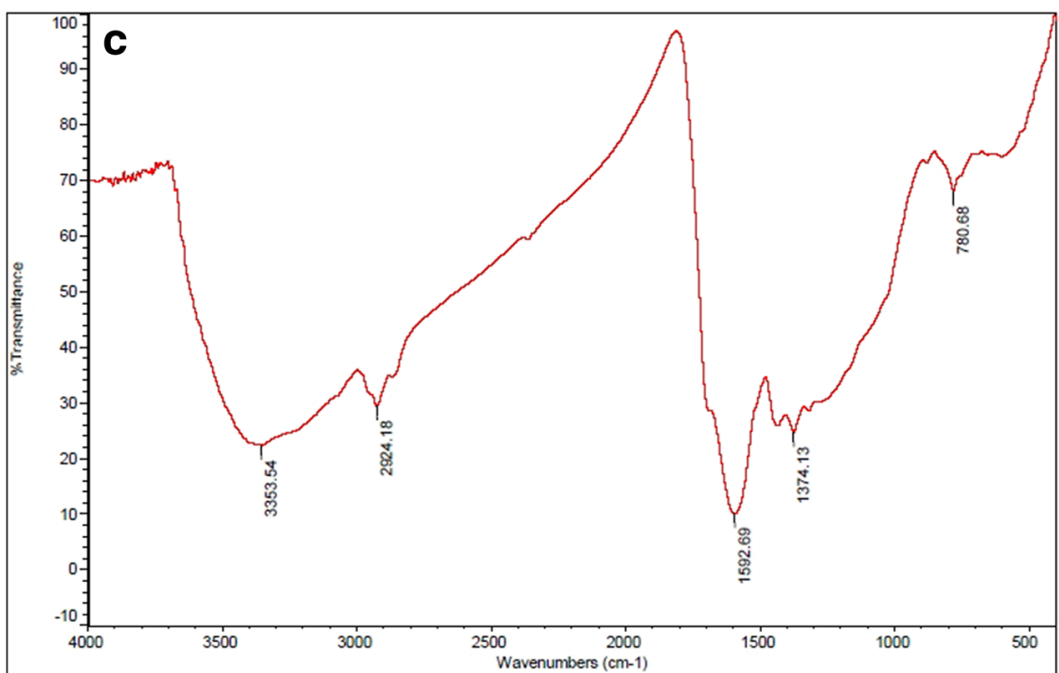

Fig. 4 Fourier transform infrared (FTIR) spectra of different biochar samples. FTIR spectrum of a pea pods; $\mathbf{b}$ cauliflower leaves; $\mathbf{c}$ orange peels 
cellulose biochar, composed almost entirely of $\mathrm{C}, \mathrm{H}$ and $\mathrm{O}$, was reported to exhibit significant anion exchange capacity (AEC) at $\mathrm{pH} 8.0$ suggesting that the $\mathrm{pH}$-independent $\mathrm{O}$ containing functional groups (oxonium, pyridinium and proton adsorption by condensed aromatic rings) contribute to AEC in biochar (Lawrinenko and Laird 2015).

The WHC was high in PP and CL biochar which can hold over 2.0 times its mass of water $(200 \%)$ followed by OP $(132 \%)$. Yu et al. (2013) reported that yellow pine biochar can hold water over 2.7 times $(\sim 270 \%)$ its mass. Several studies on addition of biochar to soil have shown the potential for increasing soil water holding capacity (Chan et al. 2007; Laird et al. 2010; Basso 2012). However, other factors like the type of biomass, carbonization process, pores, particle size and dosage also determine the WHC of biochar (Novak et al. 2009; Zolue 2013).

FTIR analysis of biochar samples for surface functional groups are presented in Fig. 4. The PP biochar showed 5 strong peaks; a peak at $3408 \mathrm{~cm}^{-1}$ corresponded to $\mathrm{O}-\mathrm{H}$ stretching carboxylic group; a peak at $1600 \mathrm{~cm}^{-1}$ indicative of conjugated $\mathrm{C}=\mathrm{C}$ phenyl rings; a peak at $1417 \mathrm{~cm}^{-1}$ corresponded to $\mathrm{C}-\mathrm{H}$ in-plane bends; a peak at $1060 \mathrm{~cm}^{-1}$ corresponding to secondary alcohol, $\mathrm{C}-\mathrm{O}$ stretch; a peak at $600 \mathrm{~cm}^{-1}$ indicating the presence of $\mathrm{C}-\mathrm{Br}$ stretch aliphatic bromo compounds (Fig. 4a). The CL biochar showed six strong peaks in the region of $3400-600 \mathrm{~cm}^{-1}$. The broad absorption peaks at $3397 \mathrm{~cm}^{-1}$ corresponding to $\mathrm{O}-\mathrm{H}$ stretching carboxylic acids; a peak at $1582 \mathrm{~cm}^{-1}$ indicating a weak aromatic ring stretch $(\mathrm{C}=\mathrm{C})$; a peak at $1437 \mathrm{~cm}^{-1}$ indicative of $\mathrm{C}-\mathrm{H}$ variable alkenes groups; a peak at $1093 \mathrm{~cm}^{-1}$ indicative of $\mathrm{C}-\mathrm{O}$ secondary alcohol stretch and a peak around at $875-602 \mathrm{~cm}^{-1}$ indicative of strong bend $\mathrm{C}-\mathrm{H}$ phenyl rings (Fig. $4 \mathrm{~b}$ ). The $\mathrm{OP}$ derived biochar peaks corresponding to $\mathrm{O}-\mathrm{H}$ at $3500-3353 \mathrm{~cm}^{-1}$; a band at $2920 \mathrm{~cm}^{-1}$ which is attributed to $\mathrm{C}-\mathrm{H}$ stretching vibration of methyl, methylene and methoxy groups; an IR band at $1592 \mathrm{~cm}^{-1}$ indicative of $\mathrm{N}-\mathrm{H}$ bend amine groups; a peak at $1374 \mathrm{~cm}^{-1}$ indicative of symmetrical stretch nitro compounds, $\mathrm{NO}_{2}$; and a peak at $780 \mathrm{~cm}^{-1}$ correlated with aromatic $\mathrm{C}-\mathrm{H}$ bending (Fig. 4c). Many chemical interactions between biochar and the environment are directly related to its surface chemistry. The presence of functional groups such as the carboxyl and hydroxyl groups suggest that all these biochar could have the possibility to be used as a soil amendment for improving of the cation exchange capacity and as a potential adsorbent ( $\mathrm{OH}$ et al. 2012).

\section{Conclusion}

A laboratory study was conducted to characterize three biomass wastes viz. Cauliflower leaf (CL), orange peels (OP) and pea pod (PP), and they were carbonized at different temperatures. The PP and CL biochar had higher values of organic carbon, total surface anions, water holding capacity and mineral content for use as a best soil amendment than OP biochar. This finding is important to establish these biochar as an effective medium for increasing soil carbon, irrigation effectiveness, runoff mitigation and reducing non-point source agricultural pollution. Apart from this, the reduction of voluminous waste biomass to produce biochar through pyrolytic process provides possible ways to solve the management and disposal of the waste biomass in an efficient manner.

Acknowledgments The authors thank TIASN, SEED, Department of Science and Technology (DST), Government of India, New Delhi, for financial assistance (Ref. No. SSD/TISN/034/2011), and Shri A.M.M. Murugappa Chettiar Research Centre, Taramani, Chennai, for providing necessary facilities to carry out this research work. The authors acknowledge the help of STIC, Cochin, for help in CHNS, SEM-EDX, TGA and FTIR analysis.

Open Access This article is distributed under the terms of the Creative Commons Attribution 4.0 International License (http://crea tivecommons.org/licenses/by/4.0/), which permits unrestricted use, distribution, and reproduction in any medium, provided you give appropriate credit to the original author(s) and the source, provide a link to the Creative Commons license, and indicate if changes were made.

\section{References}

Ahmedna M, Clarke SJ, Rao RM, Marshall WE, Johns MM (1997) Use of filtration and buffers in raw sugar color measurements. J Sci Food Agric 75:109-116. doi:10.1002/(SICI)10970010(199709)75:1

ASTM D3172-89 (2002) Standard practice for proximate analysis of coal and coke. ASTM, USA

Atkinson CJ, Fitzgerald JD, Hipps NA (2010) Potential mechanisms for achieving agricultural benefits from biochar application to temperate soils: a review. Plant Soil 337:1-18. doi:10.1007/ s11104-010-0464-5

Basso SA (2012) Effect of fast pyrolysis biochar on physical and chemical properties of a sandy soil. Graduate Theses and Dissertations. Paper 12586

Basta AH, Fierro V, El-Saied H, Celzard A (2011) Effect odeashing rice straws on their derived activated carbons produced by phosphoric acid activation. Biomass Bioenergy 35:1954-1959. doi:10.1016/j.biombioe.2011.01.043

Bohem HP (1994) Some aspects of the surface chemistry of carbon blacks and other carbons. Carbon 32:759-769. doi:10.1016/ 0008-6223(94)90031-0

Brown RA, Kercher AK, Nguyen TH, Nagle DC, Ball WP (2006) Production and characterization of synthetic wood chars for use as surrogates for natural sorbents. Org Geochem 37:321-333. doi:10.1016/j.orggeochem.2005.10.008

Budinova T, Ekinci E, Yardim F, Grimm A, Björnbom E, Minkova V, Goranova M (2006) Characterization and application of activated carbon produced by $\mathrm{H}_{3} \mathrm{PO}_{4}$ and water vapor activation. Fuel Process Technol 87(10):899-905. doi:10.1016/j.fuproc. 2006.06.005

Carrier M, Loppinet-Serani A, Denux D, Michel Lasnier J, HamPichavant F, Cansell F, Aymonier C (2011) Thermogravimetric 
analysis as a new method to determine the lignocellulosic composition of biomass. Biomass Bioenergy 35:298-307. doi:10.1016/j.biombioe.2010.08.067

Chan KY, Xu ZH (2009) Nutrient properties and their enhancement. In: Lehmann J, Joseph S (eds) Biochar for environmental management: science and technology. Earthscan, London, pp 67-84

Chan KY, van Zwieten L, Meszaros I, Downie A, Joseph S (2007) Agronomic values of green waste biochars as soil amendments. Aust J Soil Res 45:629-634. doi:10.1071/SR07109

Dugan E, Verhoef A, Robinson JS, Sohi S (2010) Bio-char from sawdust, maize stover and charcoal: impact on water holding capacities (WHC) of three soils from Ghana. World Congress of Soil Science, Soil Solutions for a Changing World, Brisbane, pp 1-6

European Biochar Certificate (2012) Guidelines for a sustainable production of biochar. European Biochar Foundation (EBC), Arbaz, pp 2-21

Fujita I, Tomooka J, Sugimura T (1991) Sorption of anionic surfactants with wood charcoal. Bull Chem Soc Jpn 64:738-740. doi:10.1246/bcsj.64.738

Gai X, Wang H, Liu J, Zhai L, Liu S, Ren T, Liu H (2014) Effects of feedstock and pyrolysis temperature on biochar adsorption of ammonium and nitrate. PLoS One 9(12):1-19

Gaskin JW, Steiner C, Harris K, Das KC, Bibens B (2008) Effect of low-temperature pyrolysis conditions on biochar for agriculture use. Trans Asabe 51:2061-2069. doi:10.13031/2013.25409

Glaser B, Haumaier L, Guggenberger G, Zech W (2001) The "Terra Preta" phenomenon: a model for sustainable agriculture in the humid tropics. Naturwissenschaften 88:37-41

Goering HK, Van Soest PJ (1970) Forage fibre analyses (apparatus, reagents, procedures and some applications). Agricultural Handbook, United States Department of Agriculture

Gomez-Serrano V, Piriz-Almeida F, Duran-Valle CJ, Pastor-Villegas J (1999) Formation of oxygen structures by air activation. A study by FT-IR spectroscopy. Carbon 37(10):1517-1528. doi:10. 1016/S0008-6223(99)00025-1

Hall DO, Rosillo-Calle F (1998) Biomass resources other than wood. World Energy Council, London

Hall DO, Rosillo-Calle F, de Groot P (1992) Biomass energy: lessons from case studies in developing countries. Energy Policy. doi:10. 1016/0301-4215(92)90148-U

Iyer PVR, Rao TR, Grover PD (2002) Biomass-Thermo-chemical characterization, 3rd edn. MNES, New Delhi

Knoepp JD, DeBano LF, Neary DG (2005) Soil chemistry. In: Neary DG, Ryan KC, DeBano LF (eds) Wildland fire in ecosystem; effect of fire on soils and water. General Technical Report RMRS-GTR 42-4, U.S. Department of Agriculture, Forest Service, Rocky Mountain Research Station, Ogden, UT, pp 53-71

Krull ES, Baldock JA, Skjemstad JO, Smernik RJ (2009) Characteristics of biochar: organo-chemical properties. In: Lehmann J, Joseph S (eds) Biochar for environmental management: Science and technology. Earthscan, London, pp 53-65

Laird D, Fleming P, Davis DD, Horton R, Wang B, Karlen DL (2010) Impact of biochar amendments on the quality of a typical Midwestern agricultural soil. Geoderma 158(3-4):443-449. doi:10.1016/j.geoderma.2010.05.013

Lawrinenko M, Laird DA (2015) Anion exchange capacity of biochar. Green Chem 17:4628-4636. doi:10.1039/C5GC00828J

Lehmann J (2007) A handful of Carbon. Nature 477:143-144. doi:10. $1038 / 447143 a$

Lehmann J, Silva JP Jr, Rondon M, Cravo MS, Greenwood J, Nehls T, Steiner C, Glaser B (2002) Slash-and-char: a feasible alternative for soil fertility management in the central Amazon. In: Proceedings of the World Congress of Soil Science, Thailand
Lehmann J, Da Silva Jr J P, Steiner C, Nehls T, Zech W, Glaser B (2003) Nutrient availability and leaching in an archaeological Anthrosol and a Ferralsol of the Central Amazon basin: fertilizer, manure and charcoal amendments. Plant Soil 249:343-357. doi:10.1023/A:1022833116184

Lehmann J, Gaunt J, Rondon M (2006) Bio-char sequestration in terrestrial ecosystems a review. Mitig Adapt Strateg Glob Change 11:403-427. doi:10.1007/s11027-005-9006-5

Lehmann J, Rillig MC, Thies J, Masiello CA, Hockaday WC, Crowley D (2011) Biochar effects on soil biota-A review. Soil Biol Biochem 43:1812-1836. doi:10.1016/j.soilbio.2011.04.022

Liu XH, Zhang XC (2012) Effect of biochar on pH of alkaline soils in the loess plateau: results from incubation experiments. Int $\mathrm{J}$ Agric Biol 14:745-750

Loow YL, Wu TY, Tan KA, Lim YS, Siow LF, Jahim JM, Mohammad AW, Teoh WH (2015) Recent advances in the application of inorganic salt pretreatment for transforming lignocellulosic biomass into reducing sugars. J Agric Food Chem 63(38):8349-8363. doi:10.1021/acs.jafc.5b01813

Lua AC, Yang T, Guo J (2004) Effects of pyrolysis conditions on the properties of activated carbons prepared from pistachio-nut shells. J Anal Appl Pyrol 72(2):279-287. doi:10.1016/j.jaap. 2004.08.001

Maia CMBF, Madari BE, Novotny EH (2011) Advances in biochar research in Brazil. Dyn Soil Dyn Plants 5(1):53-58

Novak JM, Busscher WJ, Watts DW, Amonette JE, Ippolito JA, Lima IM, Gaskin J, Das KC, Steiner C, Ahmedna M, Rehrah D, Schomberg H (2012) Biochars impact on soil-moisture storage in an ultisol and two aridisols. Soil Sci 177(5):310-320. doi:10. 1097/SS.0b013e31824e5593

Novak JM, Busscher WJ, Laird DL, Ahmedna M, Watts DW, Niandou MAS (2009) Impact of biochar amendment on fertility of a Southeastern coastal plain soil. Soil Sci 174:105-112. doi:10.1097/SS.0b013e3181981d9a

Oh TK, Choi BS, Shinogi Y, Chikushi J (2012) Characterization of biochar derived from three types of biomass. J Fac Agric, Kyushu Univ 57(1):61-66

Pappu A, Saxena M, Asolekar SR (2007) Solid wastes generation in India and their recycling potential in building materials. Build Environ 42:2311-2320. doi:10.1016/j.buildenv.2006.04.015

Putun AE, Apaydin E, Putun E (2002) Bio-oil production from pyrolysis and steam pyrolysis of soybean-cake: product yields and composition. Energy 27(7):703-713. doi:10.1016/S03605442(02)00015-4

Radlein D, Piskorz JK, Majerski P (1996) Method of producing slow release nitrogenous organic fertilizer from biomass. Eur Pat Appl 0716056:A1

Rondon M, Lehmann J, Ramírez J, Hurtado M (2007) Biological nitrogen fixation by common beans (Phaseolus vulgaris L.) increases with biochar additions. Biol Fertil Soils 43:699-708. doi:10.1007/s00374-006-0152-z

Sadaka S, Sharara MA, Ashworth A, Keyser P, Allen F, Wright A (2014) Characterization of biochar from switchgrass carbonization. Energies 7:548-567. doi:10.3390/en7020548

Schmidt MW, Noack AG (2000) Black carbon in soils and sediments: analysis, distribution, implications, and current challenges. Glob Biogeochem Cycles 14(3):777-793. doi:10.1029/ 1999GB001208

Shak KPY, Wu TY (2014) Coagulation-flocculation treatment of high-strength agro-industrial wastewater using natural Cassia obtusifolia seed gum: treatment efficiencies and flocs characterization. Chem Eng J 256:293-305. doi:10.1016/j.cej.2014.06. 093

Sohi S, Lopez-Capel E, Krull E, Bol R (2009) Biochar, climate change and soil: a review to guide future research. CSIRO Land and Water Science Report, pp 1-65 
Sohi SP, Krull E, López-Capel E, Bol R (2010) A review of biochar and its use and function in soil. Adv Agron 105:47-82. doi:10. 1016/S0065-2113(10)05002-9

Spokas KA, Cantrell KB, Novak JM, Archer DW, Ippolito JA, Collins HP, Boateng AA, Lima IM, Lamb MC, McAloon AJ, Lentz RD, Nichols KA (2012) Biochar: a synthesis of its agronomic impact beyond carbon sequestration. J Environ Qual 41:973-989. doi:10.2134/jeq2011.0069

Srikanth S, Das K, Ravikumar B, Rao DS, Nandakumar K, Vijayan P (2004) Nature of fire deposits in a bagasse and groundnut shell fire $20 \mathrm{mw}$ thermal boiler. Biomass Bioenergy 27(4):375-384. doi:10.1016/j.biombioe.2004.03.004

Stavi I, Lal R (2013) Agro forestry and biochar to offset climate change: a review. Agron Sustain Dev 33:81-96. doi:10.1007/ s13593-012-0081-1

Sugumaran P (2009) Production of activated carbon from agro-wastes for application in textile effluent treatment. Ph.D. Thesis. University of Madras

Sugumaran P, Seshadri S (2009) Evaluation of selected biomass for charcoal production. J Sci Ind Res 68(8):719-723

Sugumaran P, Priya Susan V, Ravichandran P, Seshadri S (2012) Production and characterization of activated carbon from banana empty fruit bunch and Delonix regia fruit pod. J Sustain Energy Environ 3(3):125-132

Teh CY, Wu TY, Juan JC (2014) Potential use of rice starch in coagulation-flocculation process of agro-industrial wastewater: treatment performance and flocs characterization. Ecol Eng 71:509-519. doi:10.1016/j.ecoleng.2014.07.005
Tsai WT, Lee MK, Chang YM (2007) Fast pyrolysis of rice husk: product yields and composition. Bioresour Technol 98(1):22-28. doi:10.1016/j.biortech.2005.12.005

Uzun BB, Putun AE, Putun E (2006) Fast pyrolysis of soybean cake: product yields and composition. Bioresour Technol 97(4):569-576. doi:10.1016/j.biortech.2005.03.026

Varela Milla O, Rivera Eva B, Huang WJ, Chien CC, Wang YM (2013) Agronomic properties and characterization of rice husk and wood biochars and their effect on the growth of water spinach in a field test. J soil sci plant nutr 13(2):251-266. doi:10. 4067/S0718-95162013005000022

Yagmur E, Ozmak M, Aktas Z (2008) A Novel method for production of activated carbon from waste tea by chemical activation with microwave energy. Fuel 87:3278-3285. doi:10.1016/j.fuel.2008. 05.005

Yang H, Yan R, Chen H, Zheng C, Lee DH, Liang DT (2006) Influence of mineral matter on pyrolysis of palm oil wastes. Combust Flame 146(4):605-611. doi:10.1016/j.combustflame. 2006.07.006

Yu OY, Raichle B, Sink S (2013) Impact of biochar on the water holding capacity of loamy sand soil. Int J Energy Environ Eng 4:44. doi:10.1186/2251-6832-4-44

Zolue GM (2013) Characterization of biochar prepared from three different feed stocks. Dissertation. University of Ghana 